\title{
Effect of the Altitudinal Gradient on the Structure and Diversity of the Tree Component in Monte Unango
}

\author{
Diolene Ali \\ Department of Forestry Engineering, Faculty of Agrarian Sciences, Lichinga, Mozambique
}

Email address:

dioleneali@gmail.com

\section{To cite this article:}

Diolene Ali. Effect of the Altitudinal Gradient on the Structure and Diversity of the Tree Component in Monte Unango. International Journal of Energy and Environmental Science. Vol. 6, No. 2, 2021, pp. 40-49. doi: 10.11648/j.ijees.20210602.13

Received: November 25, 2020; Accepted: January 6, 2021; Published: May 8, 2021

\begin{abstract}
The study was developed with the objective of evaluating the effect of the altitudinal gradient on the structure and diversity of the tree community on Mount Unango, for this, where 3 strata were allocated with 25 plots each, all with $100 \mathrm{~m}^{2}$. After its development, it was found in strata1, 2 and 3, a total of 1919 tree individuals distributed in 33 species, 25 genera, and 16 botanical families. The families best represented in number of species were: Fabaceae, and Caesalpinaceae. The species Catunaregam obovata, Piliostigma thonningii, Syzygium guineense, Parinari curatellifolia, Cussonia arborea and Annona senegalensis were present in all altimetric strata at Unango Mount. The diversity was: 1,9, 2,6, and 1.8 respectively for strata 1,2 and 3. Analytically there was a high similarity between the strata 1 and 2 studied with $50 \%$ in the Jaccard index (9 species in common), and lower similarity between strata 1 and 3 ( 1 species in common) with $25 \%$ of the index. The gradient studied presents a peak of diversity and richness at intermediate altitudes. And there was an abrupt transition in terms of the composition in the upper stratus $(1040 \mathrm{~m})$, which presents most of its floristic composition with characteristics of the high mountain ecosystems.
\end{abstract}

Keywords: Composition, Species, Variation, Similarity, Altitude

\section{Introduction}

\subsection{Mountain Forest}

\subsubsection{Type of Vegetation Along the Altitudinal Variation}

There are many definitions of mountains, the Convention on Biological Diversity brings us a more comprehensive one: "Mountains are characterized by distinct abiotic, biotic, social, cultural, economic and spiritual values". These areas tend to have a combination of the following physical and biological characteristics: altitude or slope of the land, diversified climate, a relatively high composition of endemic species and native species, and degrees of fragility and isolation, in their structure. A fifth of the world's landscape consists of mountains and about 2 billion people depend on their ecosystems for food, wood, fuel and minerals. About $80 \%$ of our planet's freshwater originates in the mountains [14].

In Africa, mountain forests have multiple economic, environmental, social and cultural functions. They are important in diversifying subsistence and guaranteeing food security, offering timber and non-timber forest products, human and animal health and many other environmental services, including biodiversity conservation, and watershed regulation. Among so many benefits to society, the mountains also have the capacity to capture water from the atmosphere and, through its springs, streams and rivers, supply the populations located in lower areas [2, 29].

"The forests of the sub-mountainous regions, which are also fast, such as forest on the slopes, differ from lowland forests, due to the lower height of the trees. The species born are adapted to the steep slope of the soil, and most of them have sapopemas, responsible for the stabilization of the trees" [9].

\subsubsection{Phytosociology and Its Importance}

Phytosociology is the branch of plant ecology that studies plant communities, delimiting and characterizing the types of vegetation based on floristic composition [21].

Phytosociology includes the structure and distribution in the vertical and horizontal space of plant communities at all scales of distribution, species composition and social interactions between species, in addition to the reciprocal relations of plant community and environment in which they are related. Within phytosociology the concept of community is important, and it 
can be defined as the set of all populations in a given geographical area or as the living part of the ecosystem, it is an organized unit in that it has additional characteristics to its components, individuals or populations $[1,28]$.

The knowledge of the state of the floristic composition is of fundamental importance for the knowledge of the structure of the vegetation, allowing qualitative and quantitative information about the area under study and the decision making for the best management of each type of vegetation. Thus, it is necessary to understand that different communities will have different contributions from different species, in relation to the number of individuals, their biomass or their distribution $[11,27]$.

\subsection{Altitudinal Gradient and Biological and Ecological Variation of Tree Communities}

Generally speaking, all altitude environments have common climatic attributes, in response to the elevation of the elevation level. The clearest attributes are the decrease in atmospheric pressure, partial pressure of $\mathrm{CO} 2$ and oxygen. [11]. Thus, with the decrease in atmospheric pressure, the average temperature also tends to be lower, and the capacity to retain moisture present, that is, at higher altitudes, water evaporation is expected to be lower [11]. On the other hand, an increase in solar radiation increases with altitude, although its effects are minimized by the occurrence of frequent clouds, or by topographic and relief cutouts.

\section{Literature Review}

\subsection{Mountain and Medium Altitude Forests in Mozambique}

\subsubsection{Wet Mountain Evergreen Forests}

These are composed of humid or sub-humid formations, which are located above $1300 \mathrm{~m}$ in altitude, in regions with annual rainfall of $1700-2000 \mathrm{~mm}$ (can be seen in the areas of Gorongosa, Chimanimani, Gurué, Milange, Vumba, Namuli, Tamassa and the Mueda plateau, among others). The most frequent species are: Widdringtonia whytei Rendle, Acacia abyssinica subsp. Calophylla Brenan, Podocarpus spp Niederl, Celtis gomphophylla Baker, Maesa lanceolata Forssk, Tabernaemontana stapfian Mill, Curtisia dentata Burm, Macaranga spp Thouars, Bombax rhodognaphalon Robyns, Diospyros mespiliformis Africana Milton, Welchana, Cussonia, Newtonia buchananii Baker F., Ficus spp., Uapaca spp Baill, Vitex spp [14].

\subsubsection{Semi Deciduous Humid Forests in Areas of Medium Altitude}

"The dominant and associated species also differ significantly, in which case Pteleopsis myrtifolia, Erythrophleum, Newtonia or Millettia. Temperatures are higher than in the evergreen mountain forests. The altitude varies from 700-1200 m and the forests face mainly East or Southeast, at the base and plateaus of Chimoio, Manica and Mossurize, extending delicately downwards along the ravines. The average annual precipitation is approximately $1200-1400$ $\mathrm{mm}$ and typical examples of this type are the forests of
Espungabera, Moribane, Mabongo, Marongo, Sitatonga and Amatongas" $[8,14]$.

\subsection{Miombo Forest}

Miombo is the main forest type in Mozambique and occupies approximately $2 / 3$ of the total area, mainly north of the Limpopo River [26].

The species of the genera Brachystegia and Julbernardia contribute more than $40 \%$ of the total volume. Other species with notable total volume in this stratum are Umbila (Pterocarpus angolenses Harms) and Jambirre (Millettia stuhlmannii Taub). But in turn, the word "Miombo" comes from the occurrence of one or more species of the genus Brachystegia, Julbernardia, and Isoberlin belonging to the family (Fabaceae, Subfamilia Caesalpinioideae) [23].

According to topographic and physiographic variations, the Miombo's structure and composition is modified by climate, soil and altitude. The number of species in general varies between 12-24, and most of them are deciduous and ectomycorrhizal. Studies carried out little across the country in the Miombo forests prove these results, but the study on an altitude gradient in the Moribane reserve found almost twice as much species in relation to other studies, in a sample area of just 1.6 ha $[10,12,17,19]$.

\subsubsection{Classification of Land Use and Cover of Unango}

According to the Marzoli database, the vegetation of the Unango Administrative post has approximately 8 (eight) vegetative classifications: deciduous forest, evergreen forest, forest with shifting agriculture, fields of cultivation, prairie, open forest with shifting agriculture, Shrubland and scrub areas.

The altudinal strata of the present study are located in the prairie area, in a transition zone in relation to the forest with shifting agriculture.

A prairie is considered a vast, open plain where there is little or no sign of trees or shrubs, with grasses in abundance. It occurs in regions where rainfall is too low to support the forest's way of life or in forest regions where edaphic issues favor the development of grasses and disadvantage woody plants. There are three types of grasslands: high, mixed and low [25].

The study area in particular is characterized as a mixed prairie area, since it is in a transition zone with the forest with shifting agriculture, as it has a high floristic diversity (shrubs, grasses and trees). Bearing in mind that the vegetation of Unango for the most part consists of miombo ecosystems, this transition to prairie may be closely linked to agriculture, as well as forestry.

\subsubsection{Classification of Soils at the Level of Mount Unango}

According to the aforementioned author, the soils in the province of Niassa are predominantly red in color deep medium texture, which can be oxides and / or clayey. The different types of soils can be found alone or in combination, the latter forming a soil complex. Most of the soils in these districts is a complex resulting from the combination of two or more types of soils with dominance of medium-textured red 
soil oxidizes. In isolation, there are lithic soils (in the 3 districts), unspecified sandy soils (Sanga and Lago), soils red clayey (in Sanga). These soils are also combined with each other and with the remaining types of soils that do not register isolated occurrence, forming a soil complex.

To assess the spatial distribution of soils and forest plantations now established in these districts, it is concluded that regions with deep medium red texture soils are being populated with occurrence of lithic or colluvial soils.

Specifically, for Unango the soil is predominantly red, and rich in iron oxides. these are poor in nutrients and organic matter, but the fall of leaves and their subsequent decomposition and animals, can somehow enrich them with nutrients, as in the case of nitrogen.

\section{Material and Methods}

\subsection{Description of the Study Area}

\subsubsection{Climate and Relief}

The study was carried out at Monte Unango, located in the Administrative Post of Unango, District of Sanga, in the Province of Niassa. The District of Sanga is confined to the North by the Republic of Tanzania, to the South by the District of Lichinga, to the East by the Districts of Muembe and Mavago and to the West by the District of Lago. This time, the Administrative Post of Unango is $12 \mathrm{~km}$ from the district headquarters Malulo, bordering the North with the Administrative Post of Macaloge, in the South with the Administrative Post of Lusimbesse [13].

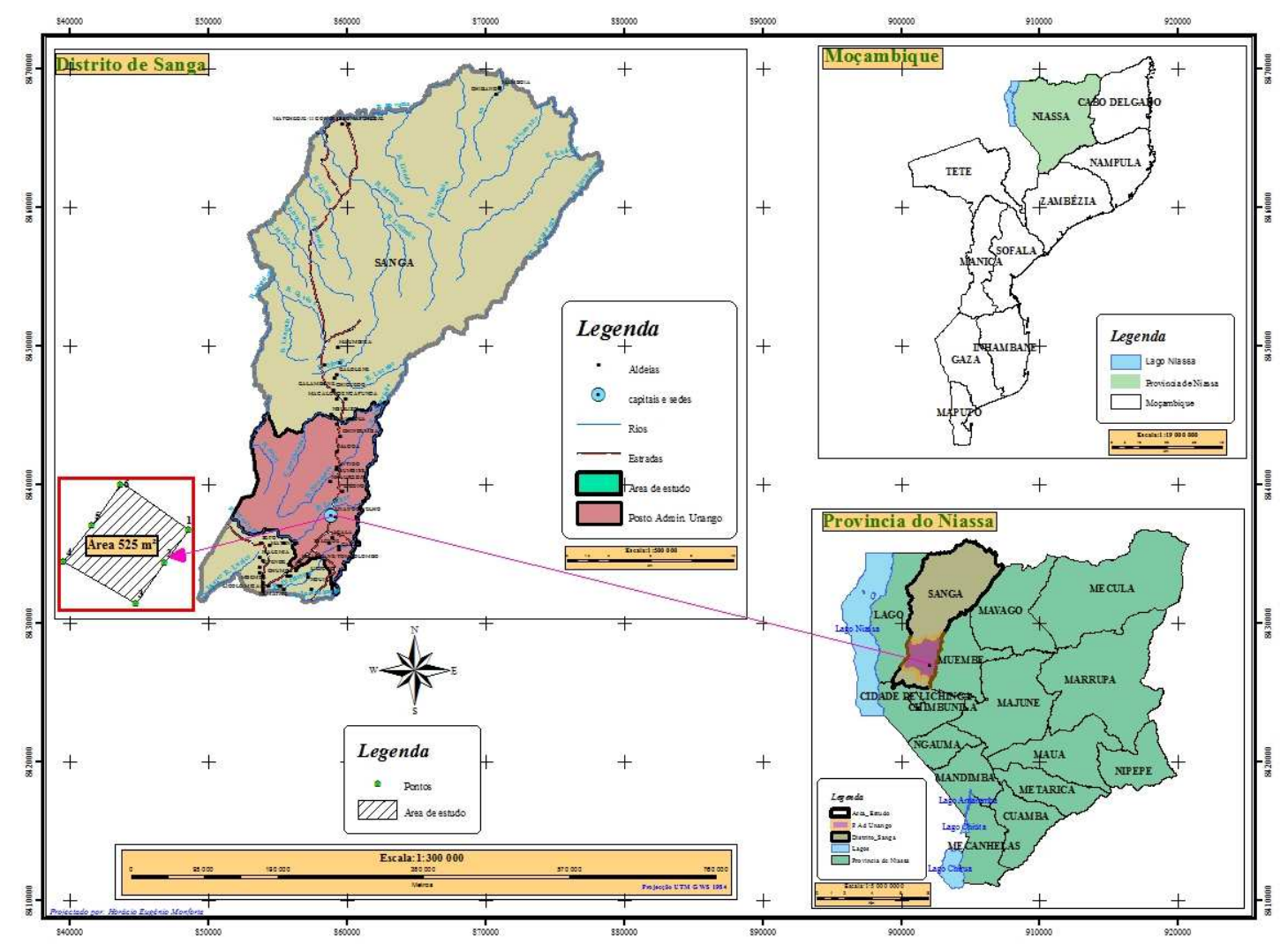

Figure 1. Map of the location of the study site.

The study strata are located in the coordinates represented by table 1 , below:

Table 1. Coordinates of the strata in the study area.

\begin{tabular}{llll}
\hline Strata & Latitude & Longitude & Altitude (m) \\
\hline 1 & $12^{\circ} 52^{\prime} 46.9^{\prime \prime}$ & $35^{\circ} 24^{\prime} 47.4^{\prime}$, & \\
2 & $12^{\circ} 53^{\prime} 12^{\prime}$, & $35^{\circ} 25^{\prime} 4.81^{\prime}$, & $1020-1040$ \\
3 & $12^{\circ} 53^{\prime} 25.3^{\prime}$, & $35^{\circ} 25^{\prime} 4.23^{\prime}$, & \\
\hline
\end{tabular}

The District of Sanga is under the influence of the Intertropical Convergence Zone, which gives rise to two well-defined seasons, namely the hot and rainy season, which runs from December to March, with April as the transition month, and the dry and cold season from May to October, with the month of November as a transition. The average annual precipitation varies between 1,000 and 1,200 $\mathrm{mm}$ in the extreme north, along the rivers Rovuma and Lucheringo, reaching the maximum of 2,000 $\mathrm{mm}$ in the highest areas of the mountain range. The average values of temperatures during the hot and humid season are 20 and $23^{\circ} \mathrm{C}$ in the plateau area and in the Cordillera de Sanga, respectively. These values increase to $23^{\circ} \mathrm{C}$ to $26^{\circ} \mathrm{C}$ in the northern strip, in the plains area, along the Rovuma River [13].

The District consists of two relief zones, namely, the Northern part of the District which is characterized by icebergs, sub-plateau areas and plains occupying about $60 \%$ of the District's territory and the South Zone occupies about $40 \%$ of the extension, being dominated by the Cordillera de Sanga with altitudes above 1,000 meters. These two zones influence the water and climatic regimes (precipitation and temperature) of the District, constituting, in turn, its agro-ecological zone [13]. 


\subsubsection{Soils and Vegetation}

The soils of the District of Sanga are predominantly clayey, red, deep and well drained, associated with humid and sub-humid climates, occupying considerable patches in the high, very rainy regions of the Cordillera de Sanga. Soils are highlighted for their high fertility and great agricultural potential, thus constituting the agro-ecological zone 10. The forest formation of the Sanga District is characterized by dry Miombo deciduous, in the North and Northeast along the Rovuma River, and late deciduous Miombo in the southern district. The Unango Administrative Post region is dominated by species of the genus Brachystegia and Uapaka. In particular, in Monte Unango the soils that are found are the following: superficial soils (Lithossolos), young soils (Cambisolos), soils deep ferralitic reds and deep gray soils [13].

\subsubsection{Hydrology}

The Unango region, specifically the Unango area, is located, from a hydrological point of view, in the Lucheringo basin. The main rivers are Lucheringo and the tributaries Luchimua and Luculece [15].

\subsection{Methods}

\subsubsection{Sampling, Size of Sample Units and Sample Sufficiency}

In the sampling and data collection, the method of fixed area plots, randomly distributed, was used in order to reduce the sampling costs and increase the precision of the estimates $[3,26]$.

For the phytosociological survey (collection of vegetation data), three collection strata were established, allocated according to the variation of altitude (which is represented by the panoramic view through figure 2 (a), and through the level curves - figure 2 (b), and the incidence of solar variation, figure 2 (c), each of the strata with 25 plots of $100 \mathrm{~m}^{2}$.

The level curves were obtained using ArcGIS 9.2 (figure b), where the variation in altitude on Mount Unango can be observed in spacing's of $20 \mathrm{~m} \times 20 \mathrm{~m}$, and the variation in altitude in the 3 concrete study strata. And for the elaboration of the radiation map, the command Area Solar Radiation (in Spatial Analyst Tools $>>$ Solar Radiation) of the ArcGIS 9.2 software was executed, to involve a raster representation that displays the apparent position of the Sun, calculated through the latitude of the area of study [27].

Through figure 2 (c), it can be seen that stratum 1 represents the most shaded area, that is, with a lower incidence of solar radiation compared to the others, stratum 2 represents the stratum with a high direct incidence of solar radiation and stratum 3 the zone with intermediate solar radiation.

By shading the contour lines, a territory model and the sunlight on that same territory, a very useful method is created (even for less trained visions) because there is an immediate overview of the morphology of the study area.
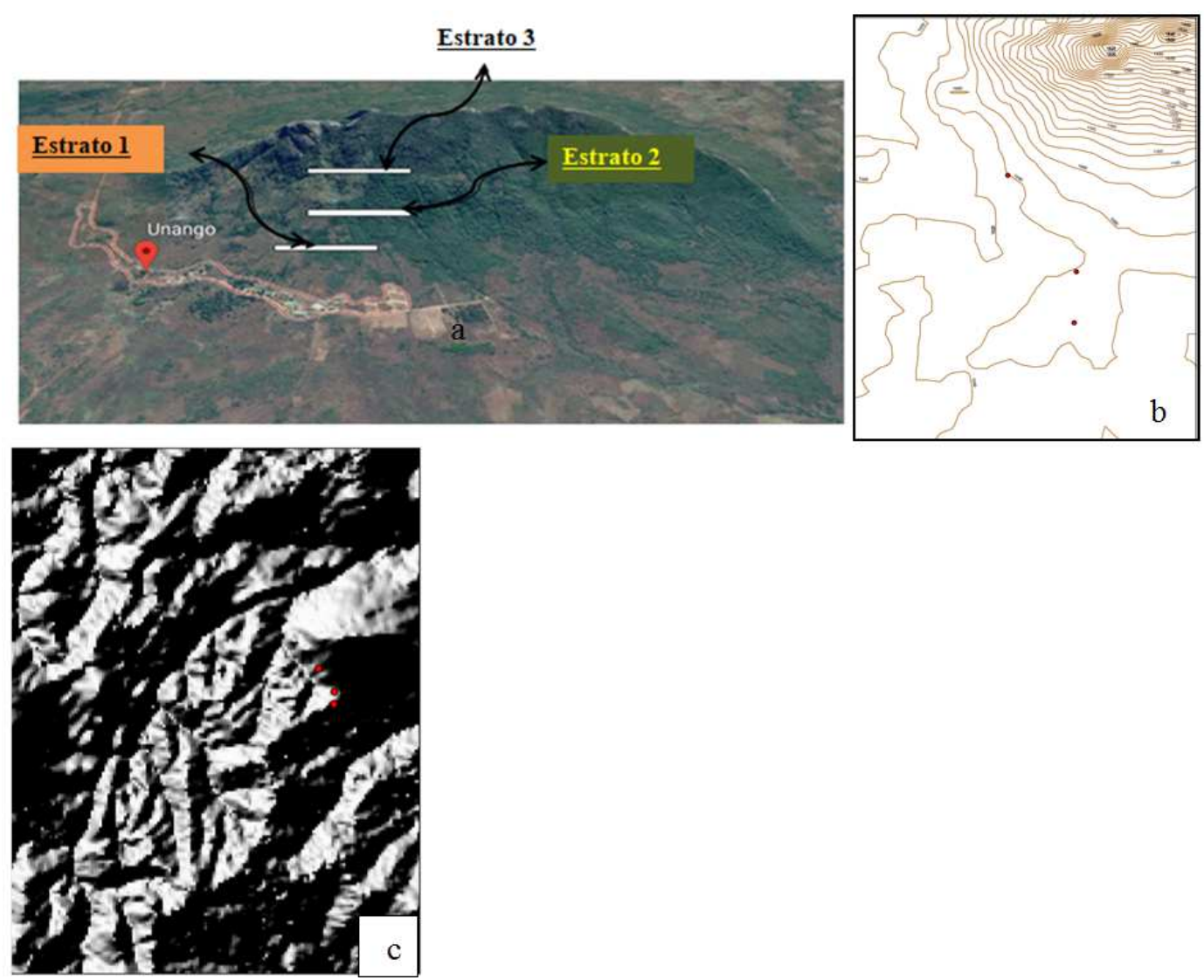

Figure 2. a. Panoramic view of Monte Unango with the three sampling sites. Source: Google Earth. b. Representation of contour lines in Monte Unango in relation to the study strata. $c$. Solar radiation incident in each of the study strata. 


\section{Inclusion and data collection criteria}

For each plot, individuals from the group of adult trees were identified and surveyed. For which, adult individuals with CAP (Circumference at Chest Height, 1.30 meters from the ground) greater than $31.5 \mathrm{~cm}$ were collected as established by Sitoe and Bila (2008). The height was estimated with reference to a $5 \mathrm{~m}$ graduated pole. For the case of individuals found with height above $6 \mathrm{~m}$, an estimate of their height was made using the length of the graduated rod.

And later the CAP values were converted to DAP using the equation:

$$
D B H=\frac{C H C}{\pi}
$$

Where:

DBH - Chest Height Diameter; CAP - Chest Height Circumference; and $\pi=3.1416$.

The botanical identification of the individuals was carried out in the field by the specific name, through their morphological characteristics, as well as through the aid of the bibliographies used to identify plant species in the Miombo savannas of Southern Africa. The nomenclature of the species was made according to the nomenclature of the International Plant Name Index. For individuals not identified in the field, their botanical material was collected for later comparison of exsiccates with dendrological Herbariums from the Faculty of Agrarian Sciences [20, 31].

\subsubsection{Sampling Sufficiency}

This was obtained based on the analysis of the collector curve, which was constructed using the Bootstrap Estimator, based on the occurrence of species and the number of plots to estimate the total of possible species to be found. Initially, a data matrix was developed (plots $\mathrm{x}$ species), based on the presence and absence of species. The calculations were performed using the EstimateS software [4].

In each of the quotas, 25 plots were installed, each with $10 \mathrm{~m} \times 10 \mathrm{~m}\left(100 \mathrm{~m}^{2}\right)$, constituting a total of $0.8 \mathrm{ha} \approx 1$ ha to be sampled. The Bootstrap estimator was chosen over the others, because it was observed that the Bootstrap distribution is closer to the statistical distribution, that is, the Bootstrap distribution has approximately the same shape and dispersion as the sample distribution (focusing on the original data collected).

\subsubsection{Vegetation Structure Analysis (Vertical and Horizontal)}

The structural analysis of the strata was centered on determining inherent aspects, to dominance, abundance, frequencies, coverage value index (IVC), the importance value index (IVI), and natural regeneration, through the database file of all plots, in order to characterize the studied tree community. Parameters related to the increase in wealth, diversity and similarity were also studied. These calculations were performed using Microsoft Excel, EstimateS 9.1.0, Primer 5.2 and Past 3.26.

These phytosociological parameters were determined considering the formulas described by [30]:

1. Density (De)

a) Absolute Density (DeA): The ratio of the total number of individuals in a taxon per area, obtained by dividing the total number of individuals in the taxon (ni) found in the sample area (A), per unit area.

$$
D e A=n_{i} / A
$$

b) Relative Density (DeR): Represents the percentage with which a taxon appears in the sample in relation to the total number of individuals in the sampled component (N). The ni / $\mathrm{N}$ ratio represents the probability that an individual randomly sampled belongs to the taxon in question.

$$
\operatorname{DeR}=\left(\frac{\mathrm{DeA}}{\sum_{\mathrm{i}=1}^{\mathrm{p}} \operatorname{DeA}}\right) * 100
$$

Where:

DeA=absolute density of the i-th species, in number of individuals per hectare;

$\mathrm{ni}=$ number of individuals of the $\mathrm{i}$-th species in the sample; $\mathrm{A}=$ total area sampled, in hectare;

$\mathrm{DRi}=$ relative density $(\%)$ of the $\mathrm{i}$-th species

2. Frequency

a) Absolute Frequency

$$
F A=\left(\frac{O c_{i}}{U A}\right) * 100
$$

Where:

(FA): Absolute frequency

(Oci): represents the relationship between the number of sampling units in which a given species occurs

(U. A.): total number of sampled units, expressed as a percentage

b) Relative frequency

$$
F R=\left(\frac{O c_{i}}{\sum O c}\right) * 100
$$

Where:

FA: Absolute frequency;

Oci=number of sample units in which a given species occurs;

$\mathrm{UA}=$ Total number of sampled units;

FR: Relative frequency

3. Dominance (Do)

a) Absolute dominance (DoA): it is the contribution of taxon i biomass in the community. It is calculated by adding the Basal Area ( $\mathrm{ABi}$ ) of all individuals of a taxon $\mathrm{i}$ (that is, of a certain species), per unit area (ha).

$$
D o A=A B_{i} / A
$$

Where: $A B=D A P^{2} * \pi / 4$

DBH - Diameter at chest height; $\pi(\mathrm{Pi}=3.1416)$

b) Relative Dominance (DoR): 


$$
D o R=\left(\frac{D o A_{i}}{\sum D o A}\right) * 100
$$

Where: DoA=Absolute dominance, DoR=Relative dominance $\mathrm{ABi}=$ Basal area of the $\mathrm{i}$-th species, in $\mathrm{m}^{2}$, in the sampled area; $\mathrm{A}=$ Area sampled in hectares

4. Importance value index (IVI):

$$
\mathrm{I} V I=D e R_{i}+D o R_{i}+F R_{i}
$$

\section{Richness}

The increase in richness in each quota was determined by counting the number of species in each sampled area. In order to compare species richness along the altitudinal gradient, a species rarefaction curve was constructed for each study quota.

For this, a binary matrix of species per plot was structured and the calculations were made using the EstimateS 9.1.0 program.

6. Diversity Index

In the present study, the Shannon Index was used as a more accurate way of verifying the diversity of species in each quota.

Shannon Index (H') - It is calculated by the formula below:

$$
H^{\prime}=\sum p i L n p i
$$

Where: $\mathrm{pi}=$ Sum of $\mathrm{n}$ individuals of each species (ni), by the total $\mathrm{n}$ individuals sampled $(\mathrm{N})=\sum \mathrm{ni}-\mathrm{n} / \mathrm{N} ; \mathrm{Ln}=$ Neperian Logarithm.

\section{Similarity}

To analyze the similarity, the venn diagram was made, based on the absence and presence of species in the altitudinal dimensions, thus showing the number of common and exclusive species of the 3 (three) altitudinal dimensions, using the Primer 5.2 software. It was also calculated the qualitative similarity index (Jaccard) between the quotas, with the aid of Software Past 3.26.

$$
\begin{gathered}
J=\left(\frac{a}{a+b+c}\right) \\
0 \leq J \leq 1
\end{gathered}
$$

Where: $\mathrm{J}=\mathrm{Jaccard}$ Similarity Index, $\mathrm{a}=$ number of common species in the strata; $b=$ number of species in stratum 1; $\mathrm{c}=$ number of species in stratum 2 .

\section{Results and Discussion}

\subsection{Floristic Composition}

\subsubsection{Species Representativeness}

In the study area, a total of 1919 individuals belonging to 33 species distributed in 26 genera of 16 families were sampled. Of these individuals, $98.12 \%$ (1883) were alive and 1.88\% (36) were dead while standing. It is important to register dead or fallen individuals, in order to know the difference between biomass and necromass, which will allow the subsequent knowledge of the carbon balance and dynamics in the plant community, as well as it will be important to designate whether or not necessary the intervention of silvicultural actions, or management activities in the area [11].

Of the total of individuals, 622 were registered for stratum 1 , 885 and 412 for strata 2 and 3 respectively.

The species richest families in the study area were Fabaceae with 9 (nine) species $(56.25 \%$ ), followed by Caesalpinaceae with 4 (four) species (25\%), Combretaceae, Mimosaceae, Myricaceae, Myrtaceae, Phyllantaceae, Verbenaceae with 2 (two) species respectively and the remaining Families with one species (Table 2).

Table 2. The 4 most representative families in number of species in the 3 strata.

\begin{tabular}{llllll}
\hline No specis/families Stratum 1 & \% Total & No species/families Stratum 2 & \% Total & No species/ families Stratum 3 & \% Total \\
\hline Fabaceae (4) & 26,32 & Fabaceae (7) & 30,43 & Fabaceae (3) \\
Caesalpiniaceae (3) & 21,05 & Mimosaceae (2) & 8,70 & Caesalpiniaceae (2) \\
Phyllantaceae (2) & 10,53 & Phyllantaceae (2) & 8,70 & Myrtaceae (2) \\
Outras 8 famílias (10) & 42,10 & Caesalpiniaceae (4) & 17,39 & Combretaceae (2) & 12,50 \\
- & - & Outras famílias (8) & 34,78 & Outras famílias (7) \\
\hline
\end{tabular}

Similar results were obtained in relation to the greater representativeness of species of the Fabaceae family in areas of fo0rest formations of Miombo in Mozambique [15, 18]. Such similarity in the results is presumed to be due, the similarities in the edaphoclimatic conditions of the same, and for the Fabaceae family to be one of the main families that make up the Miombo formations [14].

As for species richness, for stratum 1, 19 species were recorded, for stratum 2, 23 species and for stratum 3, 16 species. Figure 5 represents the rarefaction curves (accumulation of species) for each of the sampled strata, which allowed the determination of the optimal sample size based on the idea that the larger the sample size, the greater the number of species that will be found, but at a decreasing rate, to the point where the curve stabilized and became horizontal (thus determining the minimum area necessary to represent the community).

The pattern found in the present study shows that the curves of species accumulation (figure 4), were also higher for stratum 2, followed by 1 and 3 respectively, thus, based on these curves, the sample sufficiency was achieved, as it represents the floristic composition of each of the altitudinal strata. 

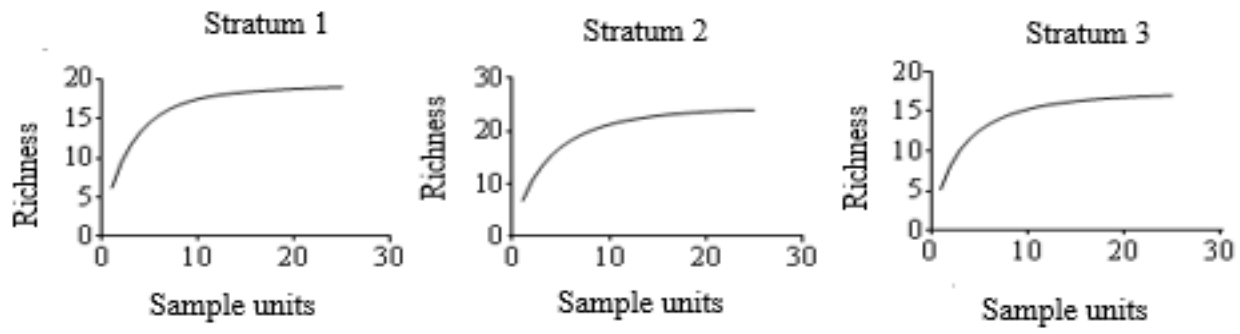

Figure 3. Rarefaction curves for strata 1, 2 and 3 respectively.

In tropical regions it is unusual to achieve stabilized curves of species accumulation, but this depends on the sampling effort [1].

When wealth estimates are calculated based on the total sampling effort, they result in higher numbers than observed, a fact that occurred in the case study, with most estimators. The high estimates are related to the occurrence of a large number of rare or less frequent species in the samples [22].

The following table illustrates a comparison between non-parametric estimators (Table 3).

Table 3. Estimated wealth of tree species by five non-parametric estimators (ICE, Chao 2, Jackknife 1, Jackknife 2 and Bootstrap), for areas 1, 2 and 3 respectively.

\begin{tabular}{llllll}
\hline \multirow{2}{*}{ Altitudinal stratum } & \multicolumn{7}{c}{ Estimators } \\
\cline { 2 - 6 } & S (Obs) & ICE & Chao 2 & Jacknife 1 & Jacknife 2 \\
\hline 1 & 19 & 19,2 & 19 & 19,96 & 20 \\
2 & 23 & 24,3 & 24 & 24,96 & 22,35 \\
3 & 16 & 17,4 & 17 & 17,96 & 18 \\
\hline
\end{tabular}

Table 3 represents the values of maximum observed wealth and determined by each of the evaluated non-parametric estimators, considering forest inventory. The values indicate the estimated average wealth.

When analyzing the values presented in Table 3, it appears that most of the estimators overestimate the maximum wealth in all strata. This can be explained by the fact that the estimators rely on the heterogeneity of the data to make their estimates.

With each occurrence of a species considered rare (see [4]), heterogeneity increases, making estimators consider a greater probability of finding new species. Thus, the estimators that came closest to the wealth found were the ICE and the Bootstrap, as they had greater accuracy and a standard deviation of \pm 0 , demonstrating to be the most accurate. For the set of data obtained in the study case, the estimator Chao 2 also stabilized with a smaller number of samples and with a small standard deviation at the end of the sample, when compared with Jacknife 1 and 2, demonstrating greater efficiency in relation to these $[24,16]$.

For an estimator to be useful, it must combine accuracy in the representation of wealth, with precision (small standard deviation), achieving stability in the fewest possible samples. The Jacknife 1 estimator was the only one that underestimated the species richness in at least two strata, being then considered to perform poorly [22].

In general, the results vary according to the researcher's experience, method used and the estimator's selection. In view of the difficulty in establishing the richness of an area, it is difficult to provide reliable answers to the performance of the estimators, since the calculations are based solely on mathematical models, without considering that the number of species in an area is constantly growing, being directly proportional to the sampling effort. Even so, new research evaluating the performance of non-parametric estimators is necessary, in Mount Unango and in the different biomes, and the studies must be carried out by experienced researchers, with the ability to recognize most species, so as not to underestimate the number of species of a given community [1, $2,7]$.

\subsubsection{Shannon-Wiener Diversity for Elevation Dimensions}

For stratum 1, a Shannon index of 1.96 was found, which corresponds to a moderate diversity. For strata 2 and 3, diversity indices of 2.62 and 1.8 were recorded respectively, both with moderate diversity, with values between 1.5-3.5. In a study carried out in Mecuburi found alpha diversity indexes around 4.5, a high diversity. This discrepancy can be justified by the occurrence of fires, which is quite frequent and intense under the vegetation on the mountain, allowing only species that best adapt to these conditions to survive [7].

\subsubsection{Analysis of Phytosociological Parameters in Each of the Quotas}

The common species Cussonia arbórea, Syzigium guineense, Parinari curatelifolia, Catunaregam obovata, Piliostigma thonningiie, Annona senegalensis that occurred in both three strata, are well distributed spatially, although the altitudinal heterogeneity of the strata themselves. However, it is possible to verify certain discrepancies in the three strata, described below: In stratum 1, the species of greatest ecological importance is Brachystegia boehmii (IVI=83.88\%), which also stood out as the most abundant species (abundance relative $=37.62 \%$ ), and the most dominant (relative dominance $=25.37 \%$ ), this with a relative frequency of $20.90 \%$, followed by Brachystegia spiciformis (IVI=65.96\%), which stood out as the most frequent in the quota (relative frequency $=21.64 \%$ ), a factor that is explained by the fact that Brachystegia spiciformis is considered the most prevalent 
species in the forests of Miombo, which adapts to its countless adversities and environmental heterogeneity [29]. The Protea caffra (IVI=29.70\%), Uapaca nitida (IVI=25.96\%), and Parinari curatellifolia (IVI=25.55) stand out (figure 5).

For this stratum an absolute dominance of $16.3 \mathrm{~m}^{2} /$ ha was determined.

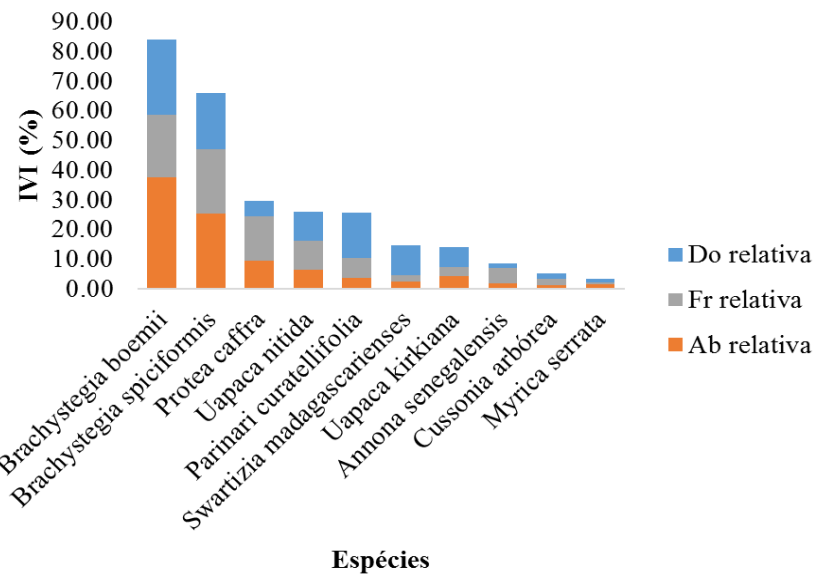

Figure 4. Behavior of species in relation to phytosociological parameters in stratum 1 .

Jubernardia globiflora is considered as one of the representative species of the miombo, but, contrary to what was expected, it does not present high values in its phytosociological parameters, which means that it has well-developed adult individuals, but still, poorly distributed in space or in a way, most of the individuals of this species, are still young, and are found in the lower strata within the community.

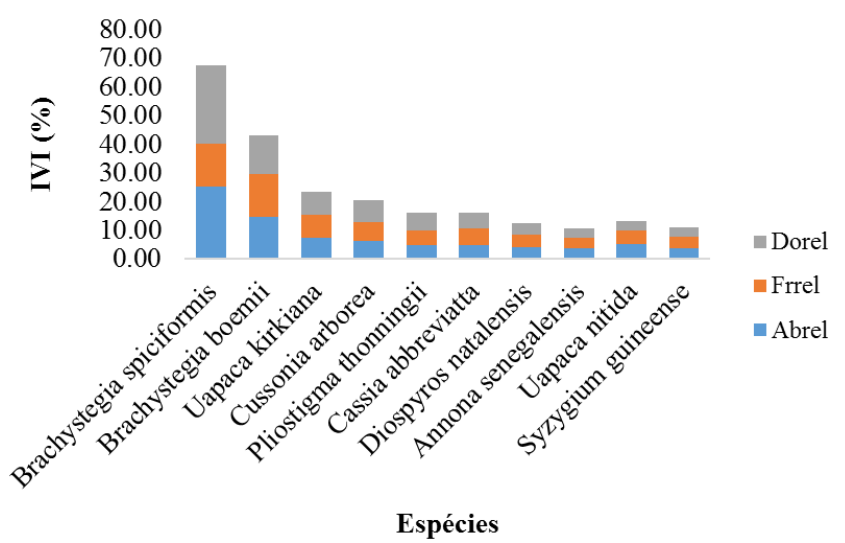

Figure 5. Species behavior in relation to phytosociological parameters in stratum 2.

In stratum 2, Brachystegia spiciformis can be seen as the species of greatest ecological importance (IVI $=67.34 \%$ ), which is also the most abundant species $(25.08 \%)$, the most frequent $(14.97 \%)$ and more dominant $(27.29 \%)$, this same species was also considered as one of the species with the highest IVI and IVC in the studies of Muhate (2004), accompanied by species such as Parinari curatellifolia. This is followed by Brachystegia boehmii (IVI=42.89\%), this being the second most abundant species (14.46\%), dominant
$(13.45 \%)$, and with the highest relative frequency as well (14.97\%), followed by Uapaca kirkiana (IVI=23.12\%), Cussonia arbórea (IVI=20.41\%) and Piliostigma thonningii (IVI $=16 \%$ ) (Figure 6). For this stratum an absolute dominance of $33.8 \mathrm{~m}^{2}$ / ha was determined.

For stratum 3, the species Terminalia mollis, stood out with the highest frequency $(18.18 \%$ ), greater abundance (relative abundance $=19.66 \%$ ) and greater dominance (relative dominance $=32.17 \%$ ), and IVI $=70.02 \%$, constituting the species of greatest ecological importance. This is followed by the species Terminalia gazensis, with $17.96 \%$ relative abundance, $17.36 \%$ relative frequency, $20.19 \%$ relative dominance, and IVI=55.51. These reveal themselves as species that adapt to environments with varied adversities such as rocky terrain, sudden climatic changes, and resist competition against the high number of grasses that are found in high altitude open forests [31]. Other species of great ecological value in this quota are Salix mucronata $(\mathrm{IVI}=23.84 \%), \quad$ Cussonia arbórea $\quad(\mathrm{IVI}=23.22 \%)$, and Diospyros natalensis with IVI $=18.34 \%$ (Figure 7). For this stratum, an absolute dominance of $54.29 \mathrm{~m}^{2} /$ ha was determined.

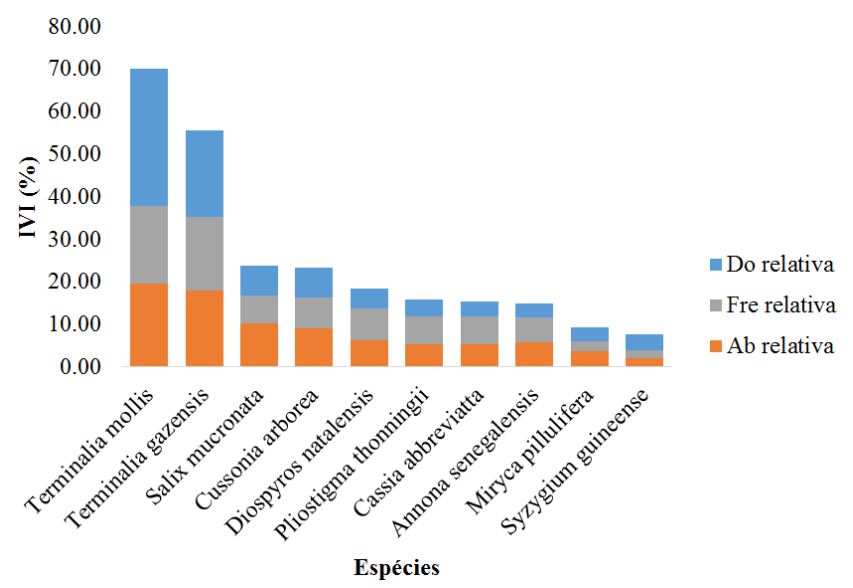

Figure 6. Behavior of species in relation to phytosociological parameters in stratum 3 .

\subsection{Similarity}

After determining the Jaccard Similarity Index, where a variation between 0.25 to 0.5 was found. It can be seen that between strata 1 and 3 , and between strata 2 and 3, the floristic similarity is very low, since the index value is below the minimum $(50 \%)$ used to consider floristically similar [1]. In general, strata 1 and 2 presented a greater number of species shared in their plots, which resulted in a $50 \%$ similarity between both in the Jaccard index (table 4).

Table 4. Demonstration of the degree of similarity between the quotas in relation to the Jaccard index.

\begin{tabular}{ll}
\hline Relationship between Strata & Jaccard similarity index value \\
\hline Stratum 1-2 & $50 \%$ \\
Stratum $1-3$ & $25 \%$ \\
Straum $3-2$ & $34 \%$ \\
\hline
\end{tabular}

Adapted by the author 
Through the Venn Diagram (figure 7), it can be seen that Stratum 3 has unique characteristics in its floristic composition in relation to strata 1 and 2 . This dissimilarity in terms of composition corroborates the alternative study hypothesis, which defends that at least one of the strata has different characteristics in its vegetal composition, since most of its exclusive species are generally typical of high mountain environments which does not happen in the other strata [31].

The wealth is relatively decreasing in relation to an ascending gradient, which consequently results in an abrupt transition in terms of floristic composition $[5,6]$.

It can also be observed that stratum 1 has 3 exclusive species (Ochna pulchra, Swartizia madagascariensis and Myrica serrate), has in common with stratum 2, 9 species (Brachystegia boehmii, Brachystegia spiciformis, Vitex payos, Protea caffra, Uapaca nitida, Uapaca kirkiana, Julbernardia globiflora, Dalbergia melanoxylon and Dichrostachys cinérea), and has in common with strata 3, 1 (one) species (Bauhinia petersiana).

Stratum 2, has 5 (five) exclusive species (Pericopsis angolensis, Pterocarpus angolensis, Brachystegia bussei, Brachystegia utilis and Acacia abyssinica), this has 3 (three) species in common with stratum 3 (Diospyros natalensis, Cassia abbreviatta, and Terminalia gazensis) and stratum 3 has 6 (six) exclusive species (Terminalia mollis, Indigofera natalensis, Ficus lutea, Vitex doniana, Salix mucronata and Myrica pillulifera). And both strata have 6 (six) species in common, they are: Cussonia arbórea, Syzigium guineense, Parinari curatelifolia, Catunaregam obovata, Piliostigma thonningii and Annona senegalensis (figure 7).

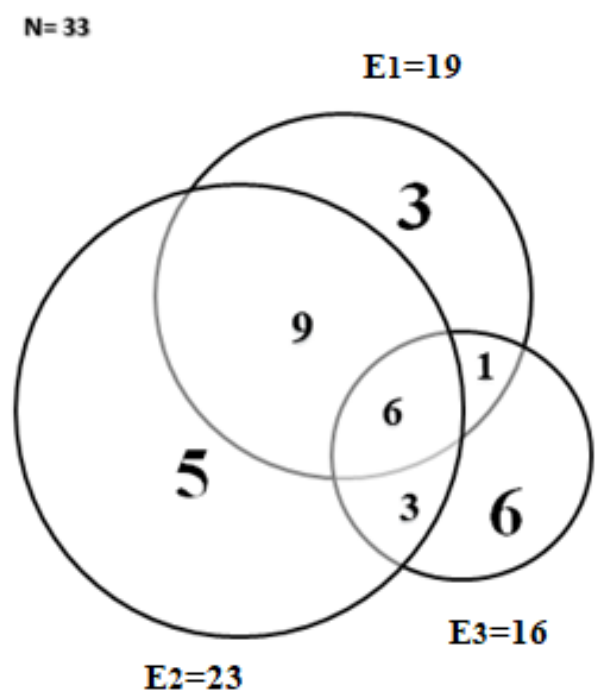

Figure 7. Venn diagram showing numbers of common and exclusive species of the tree component-E1=Stratum 1;E2=Stratum 2;E3=Stratum 3; N. number of species.

\section{Conclusion and Recommendations}

Phytosociologically for Stratum 1, the most important species in its composition stood out Brachystegia boemii, Brachystegia Spiciformis, Proteia caffra and the species of the genus Uapaca present, respectively. For Stratum 2, the species Brachystegia spiciformis, Brachystegia boemii, Uapaca kirkiana and Cusssonia arbórea, respectively. And for Stratum 3, Terminalia mollis, Terminalia gazensis, Salix mucronata and Diospyros natalensis stood out. Being highlighted for the last Stratum, a lower index of diversity (1.81) and wealth (16), since it is taken into account that altimetric regions of high mountains are characterized by endemism that works as a physical barrier in what concerns the development of certain species.

As for similarity, it can be seen through the Jaccard index, that there is a high similarity between Strata 1 and 2, and that Strata 3 stands out with less similarity in relation to the others (Strata 1 and 2), and it can be assumed that it has a more differentiated vegetation typology.

For the plant community, an alternative hypothesis (Ha) of study was accepted, that is, it was found that at least one Stratum has different characteristics in its tree composition in relation to the others, a specific case of Stratum 3, as well as another verified fact, was found the absence of characteristic miombo species of the genus Brachystegia and Julbernardia.

\section{References}

[1] AGUIAR, R. V. (2017). Phytosociology and landscaping: Identification of tree species for use in urban afforestation. Brazil: University of Passo Fundo, Faculty of Agronomy and verterinaria medicine: Graduate program in Agronomy.

[2] BACCI, D. D. (2008). Water education: Advanced studies.

[3] CAIN, S. \&. (1959). Vegetation Analysis Manual. New York: Harper \& Brothers.

[4] COLWELL, R. K. (2006). Estimates Statistical estimate of species richness and shared species of samples, Version 8.

[5] DAMASCENO, E. R. (2015.). Structure and diversity of ferns and lycophytes in an altitudinal gradient in the Atlantic Forest of Rio de Janeiro. Doctoral Thesis (Botany). National Museum, UFRJ.

[6] DAMASCENO-JÚNIOR, G. (2005). Floristic and phytosociological study of an altitudinal gradient in the Urucum Massif - Mato Grosso do Sul - Brazil. Campinas: Doctoral Thesis. Campinas State University.

[7] DAUDE, IA (2015). Structure and diversity of the arboretum's tree component on the southern slope of Monte Unango Sanga District. Unango-Mozambique: LÚRIO-Faculty of Agricultural Sciences.

[8] FREITAS, W. K., \& MAGALHÃES, L. M. (2012). Methods and parameters for studying vegetation with an emphasis on the tree strata. Forest and Environment.

[9] IBGE. (2012). Technical Manual of the Brazilian vegetation. 2nd edition. Extended magazine.

[10] KORNER, C. (2004). Mountain biodiversity, its causes and function. Ambio Special Report.

[11] KORNER, C. (2007). The use of altitude in ecological research. Trends in Ecology and Evolution. 
[12] KORNER, C., \& DIEMER, M. (1991). In situ Photosynthetic Responses to Light, Temperature and Carbon Dioxide in Herbaceous Plants from Low and High Altitude. Funtional Ecology.

[13] MAE. (2014). Profile of the district of sanga. Maputo.

[14] MARZOLI, A. (2007). Integrated assessment of Mozambique's forests. Maputos.

[15] MATE, A. \&. (1985). The soils of the unango region (Niassa Province): Terra e Agua Series: National Institute for Agricultural Research. Maputo-Mozambique.

[16] MELO, A. S. (2008). What do we gain by 'confusing' species richness and equability in a diversity index? Neotropic biota.

[17] MUHATE, A. B. (2004). Study of tree composition along an altitudinal gradient in the Moribane forest reserve. Degree Thesis. EMU.

[18] MUSSUGANHE, G. (2013). Assessment of species diversity in the coastal region of the administrative post of Praia do Bilene. Master's thesis. Eduardo Mondlane University.

[19] NSUDZULA, J. C. (2005). Composition and structure of an afromontene forest, case study: mbilambi Goba. UEM degree thesis.

[20] PLANT NAMES PROJECT. (1999). International plant name Index. Retrieved on June 30, 2020, from IPNI: https://www.ipni.org.

[21] PORTO, M. L. (2008). Plant communities and Phytosociology. Porto Alegra: UFRGS.
[22] RIBEIRO, N. \&. (2002). Tropical Forestry Manual. Faculty of Agronomy and Forest Engineering, Department of Forest Engineering, Eduardo Mondlane University.

[23] RODRIGUES, G. A. (2010). Influence of altitude on the structure of the hillside forest on the island of Marambaia - RJ. Seropédica, rj.

[24] SADIA, S., ZHANG, J., SHEAYI, A. A., TARIQ, A., \& CAO, K. (2016). Tools and techniques in plant ecology-A review. Journal of Environmental and Agricultural Sciences.

[25] SAKET, M. (1994). Report on The Updating of the Exploratory National Forest Inventory. FAO / UNDP, Moz / 92/013. Mozambique.: DNFFB.

[26] SANCHEZ, M. (2001). Floristic composition and structure of the tree community in an altitudinal gradient of the Atlantic Forest. Campinas.: Doctoral Thesis. Campinas State University.

[27] SCHORN, A. (2009). Phytosociology. Blemenau.

[28] SCHUMACHER, M. V., \& CALIL, F. N. (2005). Applied Forestry. Federal University of Santa Maria, Santa Maria.

[29] SITOE, A., \& BILLA, A. (2008). Manual for the preparation and implementation of the forest management plan. Ministry of Agriculture. Maputo.

[30] VUONO, Y. S. (2002). Phytosociological Inventory. In Methodological manual for studies in the Atlantic Forest (pp. 51-65). Rio de Janeiro: EDUR.

[31] WYK, B. V. (1997). Field Guide to trees of southern Africa. 